\title{
Aplikasi Pengarsipan Data Kliping Surat Kabar Harian Bidang Hubungan Masyarakat Kepolisian Daerah Kalimantan Selatan
}

\author{
Herpendi ${ }^{1}$, Septi Saputri ${ }^{2}$ dan Khairul Anwar Hafizd ${ }^{3}$ \\ 1,2,3)Program Studi Teknik Informatika Politeknik Negeri Tanah Laut \\ Jl. A. Yani Km.6 Ds. Panggung, Pelaihari, 70815 \\ Email: herpendi@politala.ac.id, septisaputri16@gmail.com, \\ khairul.anwarhafizd@gmail.com
}

\begin{abstract}
Public Relations Sub Division in Polda Kalsel records the clipping of daily newspapers using Microsoft Excel. Clipping data is recorded and then processed and counted types of characters, sizes, pages and coverage. At the time of recording, errors often occur so the data generated is not in accordance with the results of calculations. Therefore, a system is built that can be used to record data clipping files with automatic calculation formulas to reduce the risk of errors and incompatibility of the calculation results. This system built with web-based using the PHP programming language, so that when needed it can be opened and used quickly as it is accessible anywhere. Therefore, this system can help the Public Relations Sub Division doing its job. Based on the discussion, the system can help and facilitate public relations in the process of recording records, data calculation and monthly report generation.
\end{abstract}

Keyword : Clipping, Data Archives, Polda, Web

PENDAHULUAN

Kepolisian Daerah Kalimantan Selatan atau Polda Kalsel adalah pelaksana tugas Kepolisian RI di Wilayah Provinsi Kalimantan Selatan yang bertempat di Jl. S. Parman No.16 Kota Banjarmasin. Polda Kalsel termasuk golongan tipe A, karena berkedudukan di ibukota daerah provinsi yang memiliki banyak satuan kerja didalamnya, salah satunya adalah Bidang Humas.

Bidang Humas adalah salah satu unsur pelayanan dan pembantu pimpinan yang berada di bawah Kepala
Kepolisian Daerah (Kapolda). Unsur pembantu pimpinan bertugas mengerjakan pekerjaan yang pertanggungjawabannya langsung kepada pimpinan, yaitu Kapolda. Bidang Humas memiliki banyak pegawai dan staff yang mengerjakan berbagai tugas pokok bidang Humas. Salah satunya adalah pembuatan kliping Surat Kabar Harian.

Pembuatan kliping surat kabar harian dilakukan secara rutin setiap hari yang nantinya akan diberikan kepada Kapolda. Setelah diperiksa oleh Kapolda, kliping tersebut dikembalikan ke Bidang Humas untuk dilakukan 
pencatatan arsip kliping surat kabar harian. Pencatatan arsip kliping surat kabar harian dilakukan menggunakan aplikasi komputer, yaitu Microsoft Excel setiap harinya.

Penggunaan Microsoft Excel dalam pencatatan arsip masih kurang efisien. Data yang dicatat kerap kali terjadi kesalahan dan jumlah data tidak sesuai, sehingga hasil akhir menjadi tidak sesuai. Hal ini terjadi, karena kesalahan petugas yang bertugas untuk melakukan pencatatan arsip kliping. Padahal, seharusnya dengan adanya pencatatan arsip data yang disimpan harus disimpan secara benar dan sistematis, sehingga ketika diperlukan dapat disediakan dengan mudah dan cepat (Suraja, 2006). Oleh karena itu, penulis mengusulkan perubahan sistem pencatatan menjadi lebih efisien dengan membuat sebuah aplikasi pengarsipan kliping surat kabar harian. Aplikasi ini diharapkan dapat membantu memudahkan pegawai yang melakukan pencatatan arsip kliping surat kabar harian di Bidang Humas Polda Kalsel.

Meilinda (2016) membangun aplikasi pengarsipan dengan studi kasus pada Badan Pemberdayaan Perempuan Perlindungan Anak dan Keluarga Berencana Pontianak. Aplikasi ini digunakan untuk melakukan pengarsipan surat menyurat. Kekurangan dari aplikasi ini adalah masih berbasis desktop, sehingga hanya dapat diakses melalui aplikasi yang terpasang pada komputer admin.

Fitriani dan Pakpahan (2018) juga membangun aplikasi pengelolaan arsip pada Unit Pelayanan Pajak dan Retribusi Daerah Palmerah Jakarta. Aplikasi ini digunakan untuk melakukan pengelolaan arsip data administrasi pajak

Susanti (2017) membuat rancang bangun aplikasi pengelolahan arsip data di Laboratorium KRIMPMD (Klinik Pratama Rawat Inap Pelayanan Medik Dasar) Siti Fatimah Pare berbasis web. Namun terdapat kekurangan dari aplikasi ini, yaitu belum disediakan fitur untuk mencetak data arsip.

Simangunsong membangun sistem yang serupa dengan Susanti, tetapi dengan studi kasus yang berbeda. Simangunsong membangun sebuah sistem informasi pengarsipan dokumen surat masuk dan keluar berbasis web pada Perumnas Regional I Medan. Pada sistem ini sudah disediakan fitur filter data namun masih belum tersedia fitur cetak data. 
Pembuatan aplikasi pengarsipan data sudah banyak dilakukan seperti beberapa contoh diatas. Maka penulis juga mengangkat permasalahan yang sama yaitu pencatatan arsip dan pembuatan aplikasi berbasis web dengan fitur - fitur yang dibutuhkan.

\section{METODE}

\section{Metode Pengembangan Sistem}

Metode yang digunakan untuk pengembangan sistem adalah waterfall. Metode waterfall sering disebut dengan model sekuensial linier (sequential linear) atau alur hidup klasik (classic life cycle). Waterfall memungkinkan pendekatan perangkat lunak secara terurut, yang dimulai dari analisis hingga tahap pendukung. Metode waterfall dimulai dari analisis dari sistem yang akan dibuat.

Berikut adalah tahapan - tahapan dari waterfall menurut Rosa \& Shalahudin (2015) :

\section{a. Analisis}

Analisis merupakan tahap proses pengumpulan data dan analisis kebutuhan sistem untuk menspesifikasikan kebutuhan perangkat lunak yang akan dibuat. Penulis menggali informasi sebanyak banyaknya agar mendapatkan gambaran dan dengan mudah merancang sistem yang akan dibuat.

\section{b. Desain}

Desain merupakan tahapan pembuatan struktur data, arsitektur, representasi antar muka dan prosedur pengkodean. Pada tahap ini penulis menggunakan Entity Relationship Diagram, Data Flow Diagram dan Flowchart.

\section{c. Kode}

Kode merupakan tahap mentranlasi desain kedalam program perangkat lunak. Penulis menggunakan bahasan pemrograman Hypertext Markup Language (HTML) dan Hypertext Preprocessor (PHP) untuk pengkodean program.

\section{d. Tes}

Tes atau pegujian berfokus pada perangkat lunak pada segi logika dan fungsional serta memastikan bahwa semua bagian sudah diuji. Penulis melakukan pengujian dengan metode Black-box. Pengujian dilakukan dengan membuat kasus uji yang bersifat mencoba semua fungsi dengan memakai perangkat lunak apakah sesuai dengan spesifikasi yang dibutuhkan. 


\section{e. Pendukung dan Pemeliharaan}

Tahap pendukung dan pemeliharaan ini dapat mengulangi tahap pengembangan mulai dari tahap analisis apabila sistem yang sudah dikirimkan ke user mengalami perubahan.

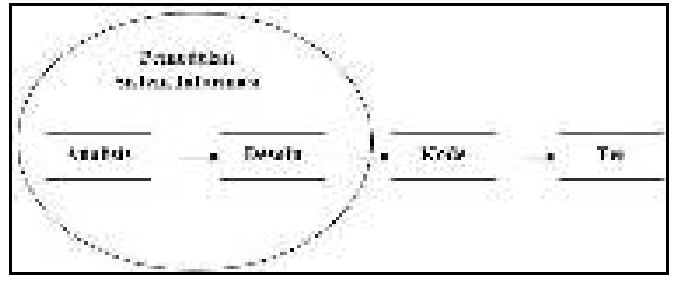

Gambar 1 Model Waterfall

(Sumber : Rosa \& Shalahudin, 2015)

\section{Tahapan Perancangan}

Sistem yang dibangun adalah sebuah website. Tahap perancangan dapat dilihat pada gambar 2. Diagram Blok pada gambar 2, mendeskripsikan tahapan perancangan sistem yang dimulai dari analisis kebutuhan, selanjutnya dilanjutkan dengan tahap pengumpulan data.

Apabila data yang dikumpulkan sudah lengkap, maka dilanjutkan dengan perancangan basis data berupa perancangan ERD dan DFD, namun apabila data yang dikumpulkan belum lengkap maka kembali ke tahap pengumpulan data. Setelah tahap pengumpulan data selesai maka dilanjutkan dengan tahap pengkodean software. Setelah tahap pengkodean selesai, maka dilanjjutkan dengan pengujian. Jika pengujian belum sesuai rancangan maka akan dilakukan perbaikan.

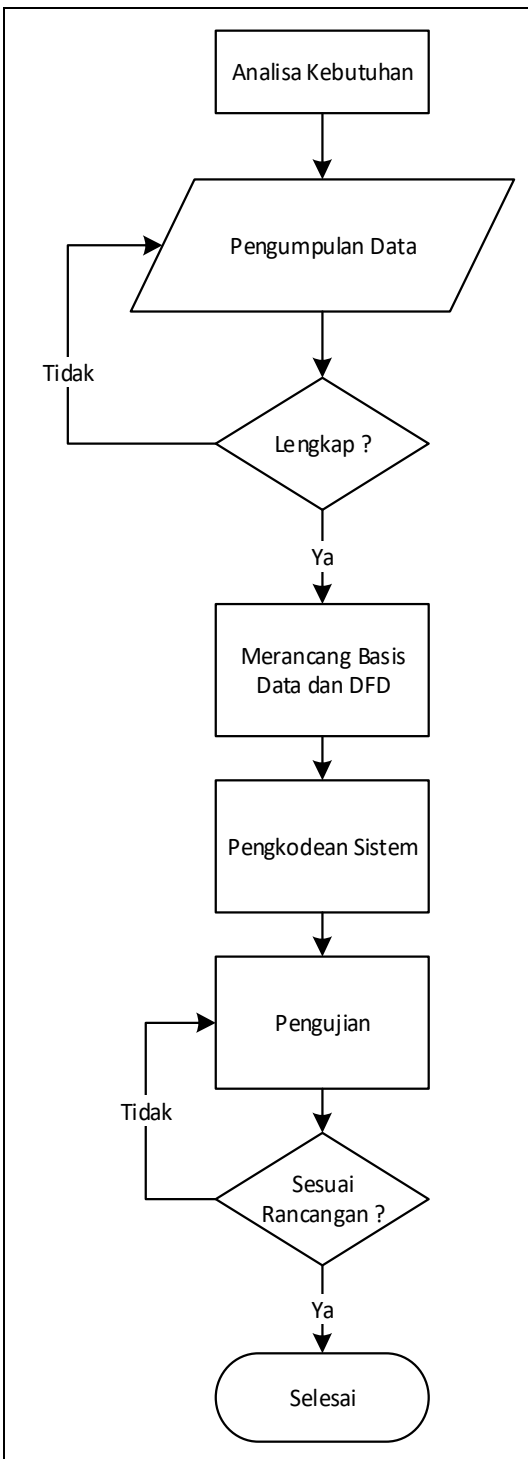

Gambar 2 Diagram Blok Tahap Perancangan 


\section{HASIL DAN PEMBAHASAN}

1. Rancangan Sistem

a. ERD

ERD dari sistem yang dibuat dapat dilihat pada gambar 3 .

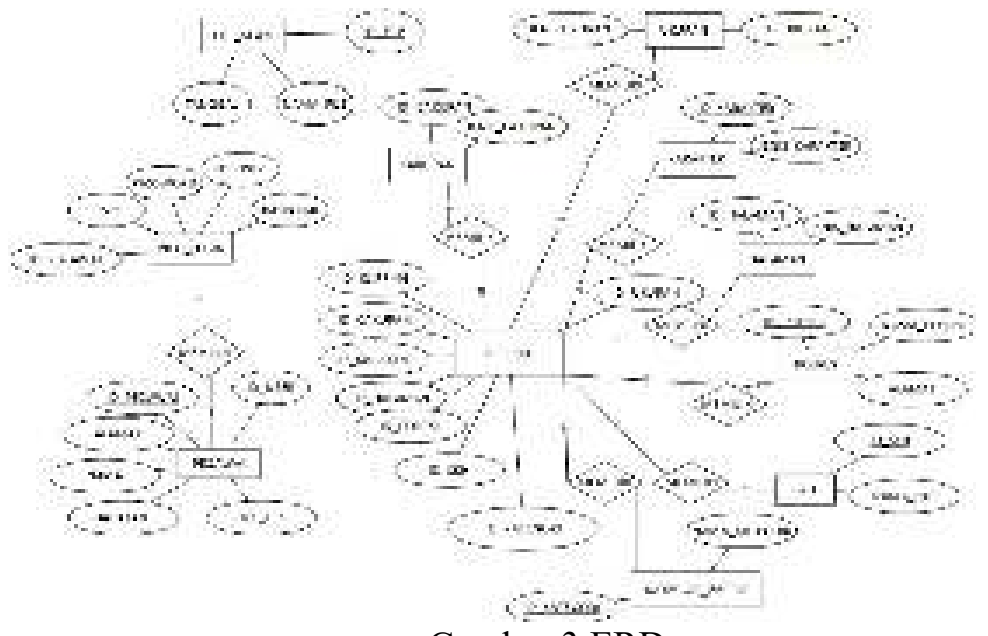

Gambar 3 ERD

Entity Relationship Diagram atau ERD menggambarkan struktur dari sebuah basis data agar mempermudah ketika merancang dan membangun basis data (Silberschatz, et al., 2009). Seperti pada gambar 3, Rancangan Entity Relationship Diagram memiliki 11 entitas, yaitu info_login, Pegawai, file_scan, klipping, cakupan, karakter, halaman, polres, ukuran, skh, dan kategori berita.

\section{b. DFD}

Data flow diagram atau DFD menggambarkan peran pengguna terhadap sistem. DFD pada sistem yang dibangun digambarkan berupa diagram Konteks yang terdiri dari entitas sebagai actor, lingkaran sebagai proses dan panah sebagai aliran data. Diagram konteks menggambarkan seluruh input kedalam sistem dan output yang dihasilkan (Sutabri, 2012).

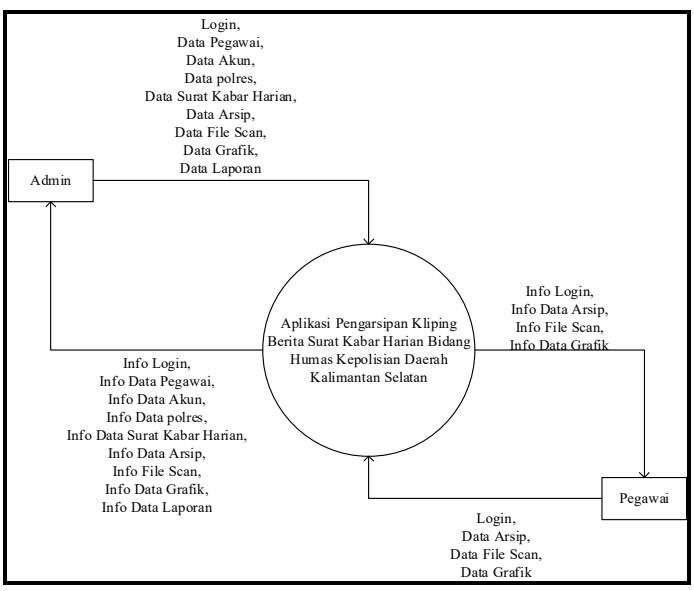

Gambar 4 DFD

Gambar 4 menggambarkan bahwa sistem memiliki 2 (dua) pengguna yaitu Admin dan Pegawai. Admin dapat melakukan input data Login, data pegawai, data akun, data polres, data surat kabar harian, data arsip, data file scan, data grafik dan data laporan. Kemudian mendapatkan output berupa info login, info data pegawai, info data akun, info data polres, info data surat kabar harian, info data arsip, info file scan, info data grafik dan info data laporan. Pegawai dapat melakukan input data login, data arsip, data file scan dan data grafik. Kemudian mendapatkan output berupa info login, info data arsip, info data file scan dan info data grafik. 


\section{Hasil}

\section{a. Halaman Login}

Pada halaman login terdapat form username dan password yang digunakan untuk memasukkan username dan password pengguna. Untuk memastikan password yang dimasukkan sudah benar dapat dicentang pada check box. Kemudian klik tombol login untuk masuk ke sistem.

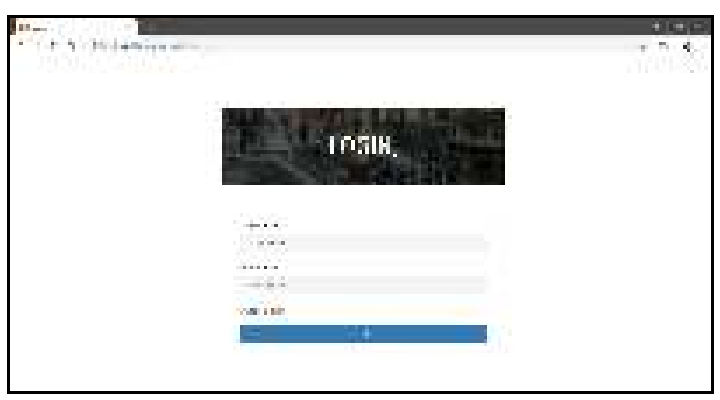

Gambar 5 Halaman Login

\section{b. Halaman Dashboard}

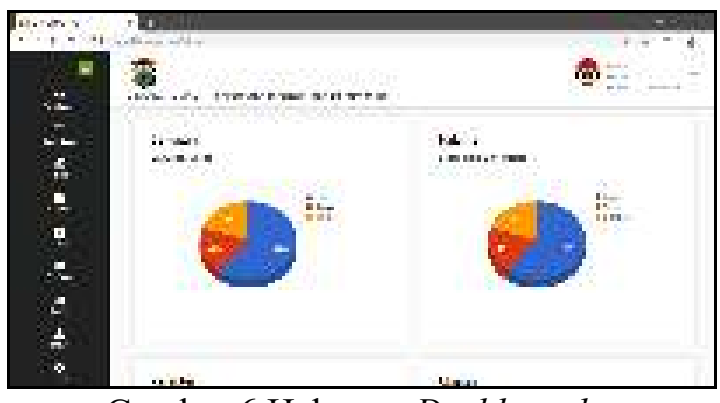

Gambar 6 Halaman Dashboard

Gambar 6 merupakan data grafik perbulan, kemudian terdapat menu menu yang dapat dipilih, seperti menu dashboard, surat kabar, polres, laporan, arsip, file scan, grafik, pegawai dan akun.

\section{c. Halaman Laporan}

Gambar 7 merupakan implementasi dari rancangan Halaman laporan. pada halaman ini menampilkan data yang sudah tersimpan.

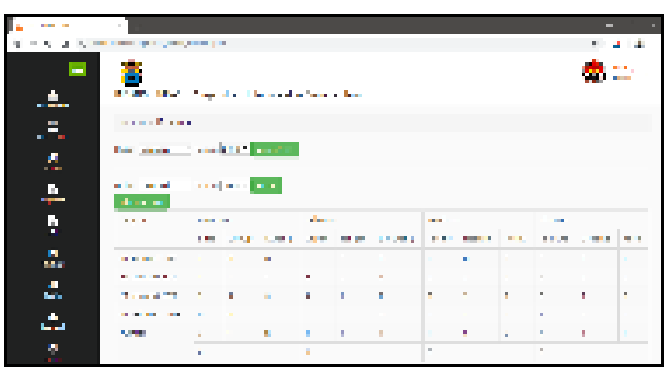

Gambar 7 Halaman Laporan

Kemudian terdapat tombol cetak yang digunakan untuk mengekspor data menjadi PDF untuk kemudian di cetak. Selain itu juga ada tombol yang digunakan untuk menampilkan data perbulan.

\section{d. Halaman Arsip}

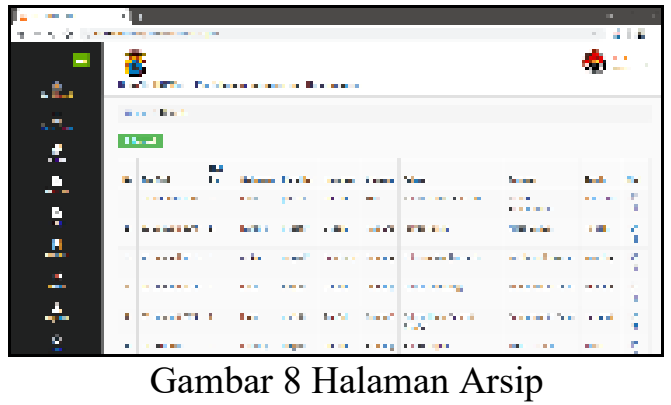

Gambar 8 merupakan tampilan data Arsip yang tersimpan di sistem. Kemudian terdapat tombol tambah yang berguna untuk mengarahkan ke halaman tambah Arsip, selain itu juga terdapat tombol ubah yang dapat digunakan untuk mengubah data Arsip. Terdapat pula tombol hapus yang digunakan untuk menghapus data. 


\section{Pengujian}

Pengujian dilakukan untuk mengetahui sejauh mana sistem dapat berjalan dan bagian mana yang terdapat kesalahan, apabila kesalahan ditemukan maka akan dilakukan perbaikan. Hasil pengujian dapat dilihat pada tabel 1 berikut :

Tabel 1 Tabel Pengujian Fungsi Sistem

\begin{tabular}{|l|l|c|}
\hline No. & \multicolumn{1}{|c|}{ Butir Uji } & Ket. \\
\hline 1. & Halaman Login & Berhasil \\
\hline 2. & Halaman Dashboard Admin & Berhasil \\
\hline 3. & Halaman Surat Kabar & Berhasil \\
\hline 4. & Halaman Tambah Surat Kabar & Berhasil \\
\hline 5. & Halaman Ubah Surat Kabar & Berhasil \\
\hline 6. & Halaman Polres & Berhasil \\
\hline 7. & Halaman Tambah Polres & Berhasil \\
\hline 8. & Halaman Ubah Polres & Berhasil \\
\hline 9. & Halaman Laporan & Berhasil \\
\hline 10. & Halaman Arsip & Berhasil \\
\hline 11. & Halaman Tambah Arsip & Berhasil \\
\hline 12. & Halaman Ubah Arsip & Berhasil \\
\hline 13. & Halaman File Scan & Berhasil \\
\hline 14. & Halaman Ubah File Scan & Berhasil \\
\hline 15. & Halaman Grafik & Berhasil \\
\hline 16. & Halaman Pegawai & Berhasil \\
\hline 17. & Halaman Tambah Pegawai & Berhasil \\
\hline 18. & Halaman Ubah Pegawai & Berhasil \\
\hline 19. & Halama Akun & Berhasil \\
\hline 20. & Halaman Ubah Akun & Berhasil \\
\hline 21. & Halaman Dashboard Pegawai & Berhasil \\
\hline 22. & Halaman Laporan Pegawai & Berhasil \\
\hline 23. & Halaman File Scan Pegawai & Berhasil \\
\hline 24. & Halaman Grafik Pegawai & Berhasil \\
\hline
\end{tabular}

\section{Pembahasan}

Berdasarkan hasil yang didapatkan dari pengujian sistem yang dibangun, sistem telah membantu dan mempermudah proses pengarsipan data kliping.

\section{a. Kelebihan sistem}

Sistem yang dibangun dilengkapi dengan pengaman berupa login saat akan masuk ke sistem. Sistem dapat diakses secara online dan dapat diakses dimana saja apabila terhubung ke internet. Admin dapat dengan mudah melakukan pencatatan dan pencarian data arsip kapanpun saat diperlukan.

Perhitungan jumlah dari data arsip yang biasanya dihitung dengan menggunakan Microsoft Excel juga tidak perlu dilakukan lagi, karena sistem dapat langsung melakukan perhitungan data dan hasilnya dapat disimpan menjadi sebuah file PDF.

\section{b. Kekurangan Sistem}

Sistem yang dibangun hanya berbasis web, sehingga jika dibuka menggunakan mobile tampilannya terkadang sedikit berbeda dan tidak rapi. Sistem juga tidak bisa diakses secara offline sehingga harus menggunakan akses internet untuk membukanya.

\section{KESIMPULAN DAN SARAN}

\section{Kesimpulan}

Berdasarkan hasil dan pembahasan, penulis mengambil kesimpulan bahwa Aplikasi Pengarsipan Data Kliping Berita Surat Kabar Harian dapat mempermudah pengerjaan pencatatan arsip, karena hasil perhitungan sudah didapatkan langsung ketika data 
ditambahkan, serta menghasilkan laporan yang akan disampaikan.

\section{Saran}

Pengembangan lebih lanjut, sebaiknya ditambah dengan fitur web mobile, sehingga kepala bidang dan sub bidang dapat dengan mudah melakukan pengecekkan laporan melalui smartphone. Selain itu, menggunakan analisis sentimen untuk mendeteksi opini dari data kliping yang akan di arsipkan.

\section{DAFTAR PUSTAKA}

Fitriani, Y. \& Pakpahan, R., 2018. Aplikasi Sistem Informasi Pengelolaan Arsip Pada Unit Pelayanan Pajak Dan Retribusi Daerah Palmerah Jakarta. Paradigma, Volume XX, pp. 51-56.

Meilinda, E., 2016. Perancangan Aplikasi Kearsipan Surat Menyurat Pada Badan Pemerintahan (Studi Kasus: Badan Pemberdayaan Perempuan Perlindungan Anak Dan Keluarga Berencana Pontianak). Khatulistiwa Informatika, Volume IV, pp. 144-152.

Rosa, A. \& Shalahudin, M., 2015. Rekayasa Perangkat Lunak Tersruktur Berorientasi Objek. Bandung: Informatika Bandung.

Silberschatz, A., Korth, H. F. \& Sudarshan, S., 2009. Database System Concept, Sixth Edition. United States: Mc Graw Hill.

Simangunsong, A., 2018. Sistem Informasi Pengarsipan Dokumen Berbasis Web. Mantik Penusa, Volume II, pp. 11-19.
Suraja, Y., 2006. Manajemen Kearsipan. Edisi Pertama ed. Malang: Dioma.

Susanti, D., 2017. Rancang Bangun Aplikasi Pengelolahan Arsip Data Di Laboratorium Kripmd (Klinik Pratama Rawat Inap Pelayanan Medik Dasar) Siti Fatimah Par. Simki-Techsain, Volume I.

Sutabri, T., 2012. Analisis Sistem Informasi. Yogyakarta: Andi. 